\title{
Availability and Characteristics of Humanitarian Health Education and Training Programs: A Web-Based Review
}

\author{
Awsan A.S. Bahattab, MBChB, MScIH; ${ }^{10}$ Monica Linty, MA; ${ }^{1}$ Monica Trentin, MA; ${ }^{1}$ \\ Claudia Truppa, MD, MSc; ${ }^{2}$ Ives Hubloue, $\mathrm{MD}, \mathrm{PhD}^{3}$ Francesco Della Corte, $\mathrm{MD} ;^{1}$ \\ Luca Ragazzoni, $\mathrm{MD}, \mathrm{PhD}^{1}$ (i)
}

1. CRIMEDIM - Center for Research and Training in Disaster Medicine, Humanitarian Aid and Global Health, Novara, Italy

2. International Committee of the Red Cross (ICRC), Geneva, Switzerland

3. Research Group on Emergency and Disaster Medicine, Vrije Universiteit Brussel, Brussels, Belgium

Correspondence:

Awsan Bahattab, MBChB, MScIH, PhD Candidate

International $\mathrm{PhD}$ in Global Health, Humanitarian Aid, and Disaster Medicine Joint Program, Università del Piemonte Orientale (UPO) and Vrije Universiteit Brussel (VUB), CRIMEDIM - Center for Research and Training in Disaster Medicine, Humanitarian Aid and Global Health Università del Piemonte Orientale Via Lanino, 1 - 28100 Novara, Italy E-mail: awsan.bahattab@uniupo.it

Conflicts of interest: The authors declare none.

Keywords: capacity building; humanitarian health; medical education; professionalization; relief work

Abbreviations:

ECTS: European Credit Transfer and

Accumulation System

EUR: Euro

MCQ: multiple choice question

NGO: nongovernmental organization

OOC: open online course

SIT: study investment time

UN: United Nations

US: United States

Received: August 10, 2021

Revised: September 14, 2021

Accepted: September 21, 2021

\section{Abstract}

Introduction: Education and training programs are critical to achieve personnel capacity building and professionalization in the rapidly growing humanitarian health sector. Thus, this study aimed to describe the status of humanitarian health education and training programs world-wide.

Methods: A web-based analysis was conducted to identify the available humanitarian health programs. The following characteristics of the training programs were described: geographical location, target audience, prerequisite, qualification, curriculum, content, length, modality of delivery, teaching and assessment methods, and tuition fee.

Results: The search identified a total number of 142 training programs, most of them available in few countries of the global North. Only seven percent of the identified programs qualified for a master's degree in humanitarian health. Public health was the most identified content (47.2\%). Approximately one-half of the training programs (50.7\%) were delivered face-to-face. Theoretical knowledge was the most common method used for teaching and assessment. The duration of the training and tuition fees were different for different programs and qualifications, while target audience, prerequisite, and curriculum design were often vaguely described or missing.

Conclusions: The study shows a global inequality in access to humanitarian health training programs due to financial and geographical constraints. The study also reveals gaps in program contents, as well as teaching and assessment methods, all issues that could be addressed by developing cost-effective e-learning and online simulation programs. Lastly, the data from this study provide a learning tool that can be used by humanitarian health educators and training centers to further define and standardize the requirements and competencies of humanitarian health professionals.

Bahattab AAS, Linty M, Trentin M, Truppa C, Hubloue I, Della Corte F, Ragazzoni L. Availability and characteristics of humanitarian health education and training programs: a web-based review. Prehosp Disaster Med. 2022;37(1):132-138.

\section{Introduction}

The number of humanitarian workers responding to crises has almost tripled in the last decade. In 2017, more than half-a-million people were employed in the field of humanitarian assistance world-wide, of whom approximately $93 \%$ were national workers. ${ }^{1}$ Humanitarian health personnel make up an essential part of the humanitarian workforce, though their exact number and specific competencies are currently unknown. ${ }^{2}$ In 2018 , the highest number of job vacancies advertised on ReliefWeb, the leading humanitarian information source provided by the United Nations (UN) Office for the Coordination of Humanitarian Affairs (OCHA; New York USA), was in the health and medicine field, ${ }^{3}$ attesting to the growing demand of skilled workers for the humanitarian health sector.

doi:10.1017/S1049023X21001333

(C) The Author(s), 2021. Published by Cambridge University Press on behalf of the World Association for Disaster and Emergency Medicine. This is an Open Access article, distributed under the terms of the Creative Commons Attribution licence (https://creativecommons.org/ licenses/by/4.0/), which permits unrestricted re-use, distribution, and reproduction in any medium, provided the original work is properly cited. 
As for other types of health-related careers, the professionalization process of humanitarian health workers consists of a set of well-defined criteria involving, besides the establishment of a defined career path, institutionalization, legitimacy, authority, and specialization of knowledge. ${ }^{4}$ Due to growing concerns about the quality and reliability of a series of humanitarian interventions, ${ }^{5-8}$ since the late 1980 s, there has been a spur of initiatives aimed to professionalize the humanitarian field. These initiatives have led to the development of new standards ${ }^{9-11}$ tools, indicators, ${ }^{12,13}$ and competencies, ${ }^{10}$ and more recently, to the creation of professional societies. ${ }^{14,15}$ In the last decades, the demand for professionalization of humanitarian assistance has also increased, with $92 \%$ of aid workers ${ }^{16}$ and humanitarian health professionals ${ }^{17}$ expressing the need for professionalization compared with only four percent of aid workers requiring the same in the 1980s. ${ }^{18}$

The growth of the humanitarian sector, together with the increasing demand for professionalization, has fostered the development and implementation of numerous humanitarian aid training programs $(>100)$ with most of them based in the global North. ${ }^{5,6}$ With regard to humanitarian health, a study by Burkle, et al has provided an overview of all the humanitarian health training programs developed in North America. ${ }^{17}$ However, the status of the humanitarian health training programs in other parts of the world, especially in the global South, is currently poorly documented. This aspect is particularly important given that a better understanding of available humanitarian health training programs would not just favor online access to pre-existing training programs, but would also enable program development and further professionalization of humanitarian health workers.

This review was conducted to identify, describe, and characterize available humanitarian health training programs world-wide. The study also aimed to identify the gaps in the existing programs and to provide some recommendations on how to mitigate these gaps.

\section{Methods}

\section{Overview}

Since the aim of this paper is to review the characteristics of humanitarian health training programs, which are not captured by published literature, a web-based search of available humanitarian health programs was conducted. The results were reported based on the web searching for systematic reviews methods ${ }^{19}$ and Preferred Reporting Items for Systematic Reviews and MetaAnalyses extension for Scoping Reviews (PRISMA-ScR) when it was applicable. ${ }^{20}$

\section{Information Sources and Search Strategy}

To identify potentially relevant websites of institutions and organizations that offer training in humanitarian health, a Google (Google Inc.; Mountain View, California USA) search of English language websites was conducted from May 15-17, 2020. A combination of the following keywords was used: [humanitarian], [humanitarian aid], [humanitarian action], [humanitarian assistance], [humanitarian emergency], [complex humanitarian emergency], [war], [violence], [armed conflict], [displaced population], or [refugee] and [health], [health care], [health system], [health service], [health worker], and [medicine], AND [training], [course], [module], [program], [education], [master], [diploma], or [certificate].

When the search result was unlimited, the first 100 websites were searched for relevant existing training programs in humanitarian health. These websites were further searched for other relevant trainings programs. Additionally, websites, training programs databases, and course directories of relevant universities, the UN, and nongovernmental organizations (NGOs), as well as open online courses (OOCs) were also searched. Finally, identified training providers were further searched for relevant training programs. The search process was concluded on July 15, 2020. Scientific papers on journal publisher websites were excluded as they do not contain the information relevant for the aim of this paper.

\section{Eligibility Criteria}

Training programs were selected for inclusion in the review based on their title, aim, and learning objectives and included, if relevant, within the study objectives. The identified training programs in disasters were included if the aim of the training program was focused on humanitarian settings. On the other hand, the identified training programs were excluded if they were focused on research skills more than technical skills (such as $\mathrm{PhD}$ programs), on a single disease, on topics unrelated to the health sector, and/or if the training program aim was not specific to the humanitarian health field.

\section{Selection of Training Programs}

The study includes all training programs delivered since 2000 that are relevant to humanitarian health and taught in the English language. Pairs of reviewers screened the training programs for inclusion independently. Inter-rater discrepancies were resolved by discussion or a third reviewer.

\section{Data Extraction and Data Items}

In order to collect data from all identified training programs, a modified model described by Ingrassia, et al was used. ${ }^{21}$ Data were extracted from official online web pages, booklets, leaflets, and brochures and collected into an Excel spreadsheet for Microsoft Office 365 (Version 2108; Microsoft Corporation; Redmond, Washington USA). The information collected included the following:

1. Geographical location of the training provider;

2. Professional background of target audience and their expertise level;

3. Enrollment prerequisites;

4. Qualification type (ie, degree, diploma, or other certificates issued by a competent authority attesting the successful completion of a recognized program of study) and academic recognition (ie, approval of the qualification from a higher education institution, type of the credit system, and number of credits earned at the end of the training);

5. Curriculum design, which is the totality of the learning experience that emphasizes either on (I) the students' ability to demonstrate knowledge of the subject content (subjectbased); (II) the students' ability to achieve the goals set by the specialists (outcome-based); or (III) the students' competence to apply knowledge, attitudes, and skills (competency-based);

6. Program content, such as clinical management, public health, epidemiology or research, health service, health system, international humanitarian law/human right/ethics and management, and staff health (self-care);

7. Program length and study investment time (SIT) by hours;

8. Training delivery modality, such as face-to-face, online, or blended;

9. Teaching and assessment methods; and

10. Tuition fee (in/or converted to Euro [EUR]). 
Synthesis of Results

The quantitative data were described using frequencies or mini$\mathrm{mum} /$ maximum values, as appropriate. Qualitative data were analyzed using content inductive analysis.

\section{Ethical Consideration}

Since the data collected for this research were publicly available on the internet, the Ethics Committee approval was deemed not necessary.

\section{Results}

A Google search identified 41 websites that provided humanitarian health training programs, and 19 of these websites provided more than one program. Additionally, websites, training programs databases, and course directories of relevant universities, the UN, and NGOs, as well as OOCs were also searched. For additional details of the identified websites and training programs, refer to Supplementary Material I (available online only). This study identified 142 humanitarian health training programs meeting the inclusion criteria. The following sections summarize the characteristics of such programs. Additional details of the training programs' characteristics are available in Supplementary Material II (available online only).

\section{Geographical Distribution}

The training providers identified by this search were based in 30 countries across five continents (the map is available as Supplementary Material III; available online only) with 18 (12.7\%) of them being OOC providers. Ninety-three (65.3\%) of the identified training programs were based in the following countries: the United States (US), the United Kingdom, Australia, Switzerland, Sweden, the Netherlands, Hong Kong, and Germany, with 29 (20.4\%) of all training programs based in the US alone.

\section{Target Audience}

Most of these training programs did not specify the professional background of their target audience $(n=95 ; 66.9 \%)$ or expertise level $(\mathrm{n}=104 ; 73.2 \%)$. When available, this type of information was inconsistent among the different training programs. Specifically, $22(15.5 \%)$ programs targeted health professionals, three $(2.1 \%)$ targeted medical doctors only, and five $(3.5 \%)$ targeted other professionals. On the other hand, for $17(12.0 \%)$ of the programs, the target audience was constituted by professionals from any related discipline (ie, health, humanitarian, social, and development organizations).

The information of the expertise level of the target audience was even more scant and vague. While few training programs were targeted to strategic $(n=13 ; 9.2 \%)$ or field officers $(n=5 ; 3.5 \%)$, others were aimed at students $(\mathrm{n}=9 ; 6.3 \%)$, students and professionals $(n=4 ; 2.8 \%)$, beginners $(0.7 \%)$, or intermediates $(0.7 \%)$.

\section{Enrollment Prerequisites}

Of the identified training programs, $27(19.0 \%)$ required applicants to have a previous degree or training, while $20(14.1 \%)$ required applicants to have previous experience. However, 93 (65.5\%) training programs did not provide information on training prerequisite.

\section{Qualification Type and Academic Recognition}

Qualification Type-Most of the identified training programs $(117 ; 82.4 \%)$ were courses, while ten $(7.0 \%)$ were master's degrees and six $(4.2 \%)$ were graduate certifications or diplomas.

\begin{tabular}{|l|c|c|}
\hline Contents & $\boldsymbol{n}$ & $\%$ \\
\hline Public Health & 67 & 47.2 \\
\hline Health Service & 24 & 16.9 \\
\hline $\begin{array}{l}\text { International Humanitarian Law/Human Right/ } \\
\text { Ethics }\end{array}$ & 16 & 11.3 \\
\hline Clinical Management & 10 & 7.0 \\
\hline Epidemiology/Research & 8 & 5.6 \\
\hline Health System & 8 & 5.6 \\
\hline Management & 7 & 4.9 \\
\hline Staff Health (Self-Care) & 3 & 2.1 \\
\hline Other & 9 & 6.3 \\
\hline Humanitarian Health (Unspecified) & 2 & 1.4 \\
\hline
\end{tabular}

Bahattab (๑) 2022 Prehospital and Disaster Medicine

Table 1. Contents

Note: Total number of topics was more than 142 (100\%) because some training programs address more than one topic.

Academic Recognition - Ninety-three of the training programs (65.5\%) allowed trainees to gain credits or points recognized by academic institutions after fulfilling the training requirements, while 28 (19.7\%) were non-credit training programs. These training programs were either standalone courses or belonging to undergraduate/postgraduate programs. These latter programs could be mandatory, selective, or elective.

Credit System-Of the 142 training programs, 120 (84.5\%) specified their credit number and system. The European Credit Transfer and Accumulation System (ECTS; $\mathrm{n}=54 ; 38.0 \%)$ and the US credit system $(n=27 ; 19.0 \%)$ were the most frequently used credit systems.

Number of Credits-The number of credits granted for these programs ranged from two to 20 ECTS and from zero-it was mandatory to attend the course as a part of an academic program - to 16 US credits. Whereas the number of credits granted for graduate certificates and diplomas was 60 and 120 ECTS, respectively, and that for masters' degrees ranged from 60 to 180 ECTS or from 45 to 80 US credits.

\section{Curriculum Design}

Information on the curriculum design was unavailable in 113 (79.6\%) programs. Training programs were either competencybased programs or being taught within competency-based programs $(\mathrm{n}=19 ; 13.3 \%)$, subject-based learning outcome programs $(n=6 ; 4.2 \%)$, or outcome-based programs $(n=4 ; 2.8 \%)$.

\section{Contents}

Content analysis revealed that public health was the most frequently addressed discipline — offered in 67 (47.2\%) courses, while clinical management was only offered in ten (7.0\%) cases. The most common topic related to public health discipline was health services and systems, which was accompanied by one or more of the following themes: (I) humanitarian system and coordination; (II) health problems; (III) epidemiological and research methods; (IV) needs assessment; (V) management; (VI) mass causalities/triage; (VII) humanitarian law, human rights, and ethics; (VIII) staff security, self-care; (IX) socio-cultural aspects in the fieldwork; (X) water, sanitation, and hygiene (WaSH); (XI) food and nutrition; and (XII) shelter and camp management. Some of these topics were also offered as separate training programs (Table 1). Among health 


\begin{tabular}{|l|c|c|c|}
\hline Program Type & $\begin{array}{c}\text { No. Courses with Available } \\
\text { Information/Total No. of Course } \\
\text { Types }\end{array}$ & Length & SIT (hour[s]) \\
\hline Course & $\begin{array}{c}\text { Length: } 78 / 117 \\
\text { SIT: } 74 / 117\end{array}$ & 60 min -10 months & $1-300$ \\
\hline Diploma & $3 / 5$ & 3 months -12 months & $1200-1800$ \\
\hline Postgraduate Certificate & $3 / 5$ & 6 months -12 months & 600 \\
\hline Master & $2 / 10$ & 11 months -24 months & 1800 \\
\hline
\end{tabular}

Table 2. Training Program Length and SIT

Bahattab @ 2022 Prehospital and Disaster Medicine

Abbreviation: SIT, study investment time.

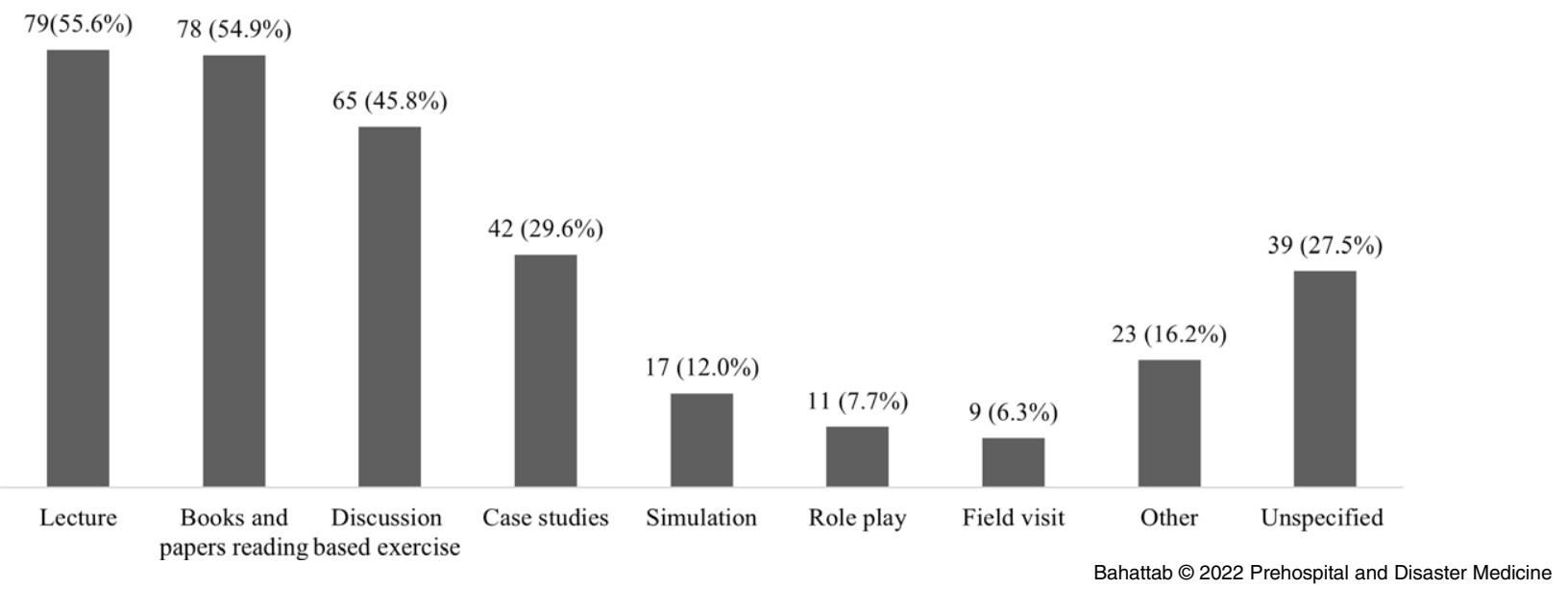

Figure 1. Teaching Methods.

Note: Total percentage of teaching methods is more than $100 \%$ because some training programs use more than one teaching method.

services, mental health was the most frequently found, followed by courses on sexual and reproductive health and non-communicable diseases.

\section{Training Program Length and SIT}

The duration of the identified training programs varied considerably, ranging from one hour to 1,800 hours. However, information on the length $(n=86 ; 39.4 \%)$ and SIT $(n=82 ; 42.3 \%)$ was unavailable in some cases. For more detailed information on course duration and SIT, see Table 2.

\section{Training Delivery Modality}

Seventy-two $(50.7 \%)$ of the identified training programs were delivered in face-to-face sessions, $43(30.3 \%)$ were delivered online, and $14(9.9 \%)$ were blended. Information was unavailable for $9.2 \%$ of the programs.

\section{Teaching and Assessment Methods}

Teaching Methods-All identified training programs used two or more teaching methods. However, information on teaching methods was unavailable for $39(27.5 \%)$ training programs. More than one-half of the identified training programs used readings $(\mathrm{n}=78$; $54.9 \%)$ and lecturing $(\mathrm{n}=79 ; 55.6 \%)$ or both as teaching material. Discussion-based exercises $(\mathrm{n}=65 ; 45.8 \%)$ and case studies ( $\mathrm{n}$ $=42,29.6 \%)$ were also frequently mentioned, while simulation was used only in $17(12.3 \%)$ cases (Figure 1).
Assessment Methods-Ninety-four of the identified training programs (66.2\%) assessed the trainees during and/or at the end of the training program, while only one $(0.7 \%)$ did not assess the trainees. However, information on the assessment methods was unavailable for 47 (33.1\%) of all programs. Individual assessment was the most common form of assessment $(n=53 ; 37.3 \%)$, while only one $(0.7 \%)$ training program exclusively used group assessment (Figure 2). Multiple choice questions (MCQs) and taskbased assessments were the most frequently employed methods for assessing trainees. Of note, only one training program $(0.7 \%)$ used simulation as an assessment method. Using multiple methods for assessing trainees was quite common $(n=48 ; 33.8 \%)$, though MCQs were also being used exclusively $(\mathrm{n}=13 ; 9.2 \%)$ as an assessment method, especially for OOCs (Figure 3).

\section{Tuition Fees}

Of the identified 142 training programs, information about tuition fees was available for $83.1 \%$. Twenty-five $(17.6 \%)$ training programs - including all OOCs - were offered without a tuition fee, with only one course requiring an administrative fee. The tuition fee for national full-time students ranged from 400 EUR to approximately 60,000 EUR, while international students were usually asked to pay higher fees. The tuition fees varied among different training programs according to the certification level, number of credits, duration, countries providing the training program, and the nationality of the students (Table 3). 


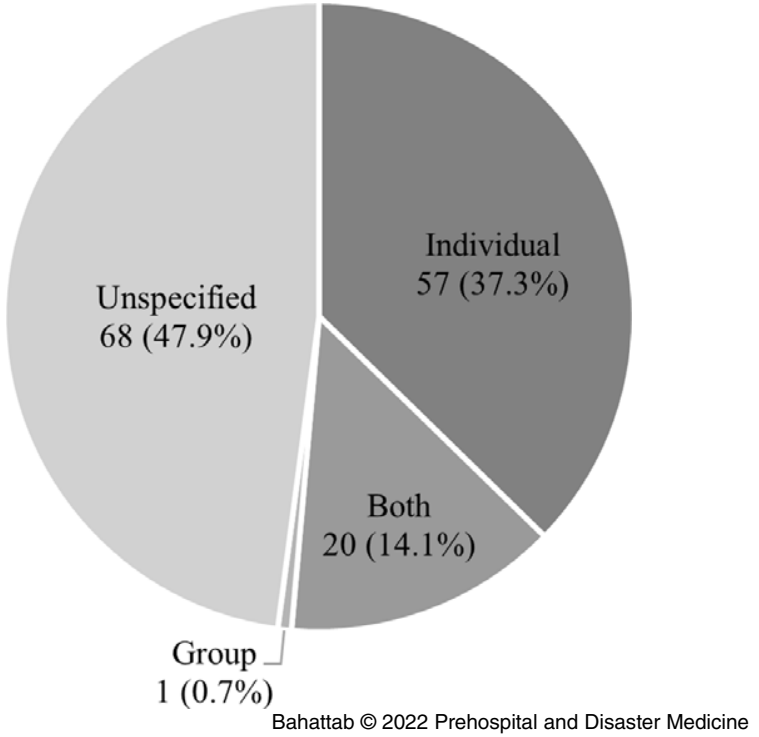

Figure 2. Type of Assessment.

\section{Discussion}

Even though in recent years the demand for skilled humanitarian health workers has rapidly grown due to the rising number of humanitarian emergencies, there is to date an evident lack of skilled and expert humanitarian personnel. ${ }^{7,8,22}$ Indeed, it is well-established that the effectiveness of the humanitarian response strictly depends on the competencies developed by humanitarian workers through education and training programs. ${ }^{23}$

The findings of this comprehensive web-based analysis of currently available education and training programs in humanitarian health may be used by key stakeholders, such as health care providers, employers, sponsors, and educational institutions, to foster the professionalization of humanitarian responders, especially in under-served geographical areas where it is needed the most.

This study was able to identify and characterize 142 humanitarian health training programs world-wide: 18 (12.7\%) of them were
OOC training programs, while the remaining 124 (87.3\%) were based in 30 countries. In this regard, it is important to stress how only a few humanitarian health training programs are currently available to people living in regions affected by humanitarian emergencies, while the vast majority of training programs are based in a limited number of developed countries, a trend consistent with the distribution of other humanitarian training programs worldwide. ${ }^{24}$ Furthermore, besides geographical constraints, high tuition costs appear to constitute an additional barrier to access accredited training programs by local humanitarian health responders from the global South. ${ }^{1,4}$ These access barriers are then likely to further widen the gap between the global North and the global South in terms of political power and leadership in humanitarian operations. ${ }^{25} \mathrm{~A}$ solution to this problem may be represented by the implementation of online training programs, which would allow health care professionals and students from all over the world to access affordable and high-quality humanitarian health training. ${ }^{26}$ This solution would be particularly attractive during periods of humanitarian crisis and pandemics, when face-to-face training and traveling are often banned despite the urgent need for such activities. A limitation to this approach is due to the fact that most of the identified online training programs are OOCs, which may pose a challenge for training recognition.

One-hundred twenty (84.5\%) of the identified training programs specify credit numbers and system. This facilitates training recognition and credit transfer between different academic institutions, thus improving the trainees' options for training selection based on their specific needs. Also shown is the existence of different types of training programs ranging from short-term, focused on specific skills, to long-term, providing a comprehensive specialization in humanitarian health, which allows humanitarian health workers to choose the training course that best suits their needs. ${ }^{21}$

Most of the training and assessment methods identified in this study were theory-based, with only a minor emphasis on learning skills. This lack of hands-on learning may be overcome by the implementation of online-based simulations, which would ensure greater accessibility ${ }^{26}$ while providing effective and efficient training and assessment methods for cognitive skills and decision making. ${ }^{27-29}$

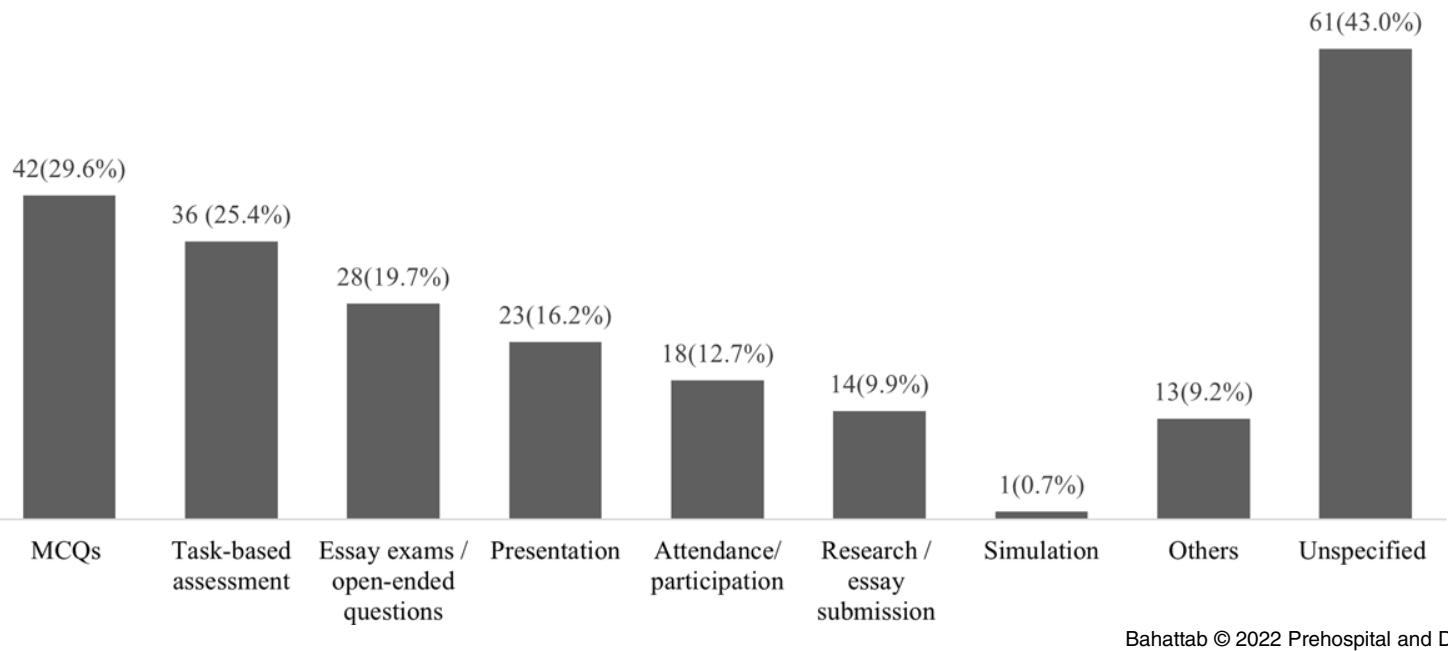

Figure 3. Assessment Methods.

Note: Total percentage of assessment methods is more than $100 \%$ because some training programs used more than one assessment method.

Abbreviation: $\mathrm{MCQ}$, multiple choice question. 


\begin{tabular}{|l|c|}
\hline Program Type & $\begin{array}{c}\text { Estimated Range of Tuition Fee } \\
\text { (EUR) }\end{array}$ \\
\hline Course $(n=61)$ & $400-15,859$ \\
\hline Diploma $(n=2)$ & $650-933.36$ \\
\hline Postgraduate Certificate $(n=4)$ & $2,653.20-6,771.33$ \\
\hline Master $(n=8)$ & $9,000-59,157.77$ \\
\hline
\end{tabular}

Bahattab @ 2022 Prehospital and Disaster Medicin

Table 3. Tuition Cost

Note: All fees were converted to Euro (EUR).

In a humanitarian health worker survey, the respondents rated "needs assessment" and "public health" as essential knowledge for all humanitarian workers. ${ }^{17}$ Fittingly, this study found that public health was the most frequently addressed topic in the identified humanitarian health training programs. This is particularly relevant if one were to consider that to Niescierenko, et al, the gaps in global health competencies have been associated with poor knowledge about specific public health areas, such as humanitarian principles and architecture, outbreak investigation, and surveillance. ${ }^{22}$ Although being generally addressed in public health courses, these topics are often disregarded in short, specific courses.

Another important issue is that humanitarian responders also lack operational skills, such as management and leadership, or are unable to transfer their skills into the humanitarian context. ${ }^{19}$ Consistently, the analysis reveals that management is at a low level of consideration ( $n=7 ; 4.9 \%)$. Importantly, most of the identified humanitarian health training programs are courses taught in the context of public health, international health, and/or global health master's programs, while a fewer number of these courses are present in humanitarian aid master's programs. Thus, explaining why trainees are often unable to transfer their skills into the humanitarian field. Also, few identified training programs have competency-based curricula, although this study was unable to ascertain whether these competencies were related to the humanitarian sector or to other fields.

The identified training programs tended to have a high rate of missing data available online. For instance, missing information on the target audience $(n=104 ; 73.2 \%)$ and curriculum $(n=113$; $79.6 \%$ ) were high. This indicates insufficient clear communication and dissemination of information and may indicate a lack of standard competencies and requirements among humanitarian health professionals.

\section{Limitations}

Finally, this study has several limitations. The keywords used to identify the training programs through Google search may have failed to uncover all related websites. To minimize this risk, the search included a secondary review of retrieved websites, seeking other programs, and humanitarian health education databases, directories, and OOCs. Non-English training programs were not searched, and this could have led to the lack of data from the global South. Missing data could be the result of the extraction from publicly available sources online, even though more information may have been available from direct queries to the identified training programs, this approach was beyond the scope of this study, which was simply to provide an overview of the current status of humanitarian health training and education world-wide as a basis for further inquiries by scholars in this field.

\section{Conclusions}

The study identified 142 available training programs in humanitarian health education world-wide. Despite their growing number, these existing programs are characterized by numerous gaps and barriers. Most of these programs are located far from where they are needed the most, and most of them are too expensive for low-income students. Additionally, most teaching and assessment methods of the available programs are exclusively based on theoretical knowledge transfer.

This leads to the recommendation of the development of e-learning platforms, including online simulation scenarios, for training and assessment of local humanitarian responders. Analysis also shows several inconsistencies and gaps when defining the target audience, SIT, curriculum design, and content. This observation calls for a joint collaborative effort between humanitarian societies and academia, aimed to better define and standardize the requirements and competencies of humanitarian health programs.

\section{Author Contributions}

$A B, L R$ conceived the study and designed the search strategy. AB, MT conducted the searches, screened training programs websites, and retrieved the data. $\mathrm{AB}$ wrote the first draft of the manuscript. All authors provided critical input in the analysis, edits, and approved the last version of the manuscript.

\section{Acknowledgements}

This manuscript is the result of a study conducted in the framework of the International $\mathrm{PhD}$ in Global Health, Humanitarian Aid, and Disaster Medicine jointly organized by Università del Piemonte Orientale (UPO) and Vrije Universiteit Brussel (VUB).

\section{Supplementary Material}

To view supplementary material for this article, please visit https:// doi.org/10.1017/S1049023X21001333

\section{References}

1. Active Learning Network for Accountability and Performance (ALNAP). The state of the humanitarian system 2018. London, England: ALNAP Study; 2018. https://sohs.alnap.org/help-library/the-state-of-the-humanitarian-system2018-full-report. Accessed September 27, 2020.

2. Kene M, Pack ME, Greenough PG, Burkle FM. The professionalization of humanitarian health assistance: report of a survey on what humanitarian health workers tell us. Prehosp Disaster Med. 2009;24(Suppl 2):s210-s216.

3. United Nations Office for the Coordination of Humanitarian Affairs (OCHA). World humanitarian data and trends 2018. United Nations; 2018. https://www.unocha.org/ sites/unocha/files/WHDT2018_web_final_spread.pdf. Accessed September 27, 2020.

4. James E. The professional humanitarian and the downsides of professionalization. Disasters. 2016;40(2):185-206.

5. Cranmer H, Chan JL, Kayden S, et al. Development of an evaluation framework suitable for assessing humanitarian workforce competencies during crisis simulation exercises. Prehosp Disaster Med. 2014;29(1):69-74.

6. Johnson K, Idzerda L, Baras R, et al. Competency-based standardized training for humanitarian providers: making humanitarian assistance a professional discipline. Disaster Med Public Health Prep. 2013;7(4):369-372.

7. Amat Camacho N, Hughes A, Burkle FM, et al. Education and training of emergency medical teams: recommendations for a global operational learning framework. PLoS Curr. 2016;8.

8. Colombo S, Pavignani E. Recurrent failings of medical humanitarianism: intractable, ignored, or just exaggerated? Lancet. 2017;390(10109):2314-2324.

9. Sphere. Geneva, Switzerland: Sphere; 2020. https://spherestandards.org/. Accessed October 6, 2020 
10. CHS Alliance. Geneva, Switzerland: CHS Alliance; 2020. https://www.chsalliance. org/about/. Accessed October 6, 2020.

11. Emergency medical team (EMT). Geneva, Switzerland: WHO; 2020. https:// extranet.who.int/emt/. Accessed October 6, 2020.

12. Active Learning Network for Accountability and Performance (ALNAP). Active learning network for accountability and performance in humanitarian action. London, England: ALNAP; 2020. https://www.alnap.org/. Accessed October 6, 2020.

13. Enhanced Learning and Research in Humanitarian Assistance (ELRHA). Cardiff, United Kingdom: ELRHA; 2020. https://www.elrha.org/. Accessed October 6, 2020.

14. Professionals in Humanitarian Assistance and Protection (PHAP). International association of professionals in humanitarian assistance and protection. Brussels, Belgium: PHAP; 2020. https://phap.org/. Accessed October 6, 2020.

15. The Association of Academic Training Centers in Humanitarian Health (PAATCHH). Center for human rights and humanitarian studies. Providence, Rhode Island USA: Watson Institute, Brown University; 2020. https://watson.brown.edu/chrhs/partnerships/paatchh. Accessed October 6, 2020.

16. Walker P, Hein K, Russ C, Bertleff G, Caspersz D. A blueprint for professionalizing humanitarian assistance. Health Aff. 2010;29(12):2223-2230.

17. Burkle FM, Walls AE, Heck JP, et al. Academic affiliated training centers in humanitarian health, Part I: program characteristics and professionalization preferences of centers in North America. Prehosp Disaster Med. 2013;28(2):155-162.

18. Burkle Jr. FM, Lyznicki JM, James JJ. “Cross-disciplinary competency and professionalization in disaster medicine and public health.” In: Gursky E, Hrečkovski B, (eds). Handbook for Pandemic and Mass-Casualty Planning and Response. NATO Science for Peace and Security Series - E: Human and Societal Dynamics. Amsterdam, The Netherlands: IOS Press; 2012:72-83.

19. Briscoe S. Web searching for systematic reviews: a case study of reporting standards in the UK Health Technology Assessment program. BMC Res. 2015;8:1-7.
20. Tricco AC, Lillie E, Zarin W, et al. PRISMA extension for scoping reviews (PRISMA-ScR): checklist and explanation. Ann Intern Med. 2018;169(7): 467-473.

21. Ingrassia PL, Foletti M, Djalali A, et al. Education and training initiatives for crisis management in the European Union: a web-based analysis of available programs. Prehosp Disaster Med. 2014;29(2):115-126.

22. Niescierenko M, Fischer H, Prager G, Nilles E. Strengthening global capacity for emergency health action. 2019. Health Cluster. https://www.who.int/health-cluster/partners/ current-partners/emergency-response-capacity-report.pdf. Accessed October 6, 2020.

23. Jacquet GA, Obi CC, Chang MP, Bayram JD. Availability and diversity of training programs for responders to international disasters and complex humanitarian emergencies. PLoS Curr. 2014;6.

24. Rainhorn JD, Smailbegovic A, Jiekak S. University training and education in humanitarian action. Geneva, Switzerland; 2010. https://reliefweb.int/report/world/ humanitarian-studies-2010-university-training-and-education-programmes-humani tarian. Accessed October 3, 2020.

25. Roth S. Professionalization trends and inequality: experiences and practices in aid relationships. Third World Q. 2012;33:1459-1474.

26. Della Corte F, La Mura F, Petrino R. E-learning as educational tool in emergency and disaster medicine teaching. Minerva Anestesiol. 2005;71(5):181-195.

27. Cook DA, Hatala R. Validation of educational assessments: a primer for simulation and beyond. Adv Simul (Lond). 2016;1:31.

28. Straus SG, Lewis MW, Connor K, et al. Collective simulation-based training in the US Army: user interface fidelity, costs, and training effectiveness. Santa Monica, California USA: RAND Corporation; 2019. www.rand.org/t/RR2250\%0ALibrary. Accessed September 12, 2020.

29. Burkle FM, Kushner AL, Giannou C, Paterson MA, Wren SM, Burnham G. Health care providers in war and armed conflict: operational and educational challenges in international humanitarian law and the Geneva Conventions, Part II. Educational and training initiatives. Disaster Med Public Health Prep. 2018;13(3):383-396. 